Parubets S. O., Student Kyiv National Economic University named after Vadym Hetman

Kyiv, Ukraine

DOI: https://doi.org/10.30525/978-9934-26-064-3-7

\title{
ASSESSMENT OF INNOVATION GAP BETWEEN HIGH-INCOME AND LOW-INCOME COUNTRIES
}

Global challenges and the need for innovations go hand in hand. Whether they are caused by the increasing interdependence of economies, deepening digitalization, or the unforeseen challenges caused by the global pandemic of COVID-19, innovations are reflective responses to societies' need for effective long-term solutions.

Innovation is one of the most significant sources of unique resources and assets that form competitive advantages, not only for local economic actors and companies but also for multinational corporations, international institutions, policymakers, and countries. Industries and businesses, whether global or not, have embraced innovations as a source of long-term growth, rising productivity and well-being.

In essence, innovation can be understood as a change resulting from the creation of new technological knowledge and its introduction into the market [1, p. 19].

Multinationals are active in identifying the global frontier of technological expertise hence being key players in the global 
innovation process. Multinational companies, as the primary developers of applied research and technology, act as an important medium for the dissemination of inventions and developments across national borders.

The role of innovation as a catalyst of long-term growth has become central in a number of countries' economic policies respective to multinational corporations. However, this pursuit of both creativity and long-term viability, technology, and know-how transfer can be seen as the key connection between multinational corporations and national economies. The relationship between multinational corporations, industrialized and emerging economies is especially significant in this regard.

The peculiar origin of the innovation gap between countries with advanced and emerging economies can be explained by the definition of innovation itself. An invention has a chance to be put into practice, either directly or by making it accessible to other groups, businesses, individuals, or organizations. The dissemination and uptake of similar technologies direct the economic and social impacts of inventions and ideas. Likewise, innovation is a complex and widespread phenomenon that exists in all sectors of the economy therefore it is not limited to the business sector. These complex and diverse behaviors and relationships pose major, but not insurmountable, challenges yet the management and economics sciences provide the basis for innovations assessment.

According to OECD, management perspectives on innovation cover how innovation can change a firm's position in the market and how to generate ideas for innovation. Economic perspectives examine why organizations innovate, the forces that drive innovation, the factors that hinder it, and the macroeconomic effects of innovation on industry, market, or economy [2, p. 45].

The differentiation of the countries' economies is important for the innovation processes. The level of economic development is influencing on: resources to be used for producing and dissemination of innovations, national economy capacity to utilize innovations, 
quality of human resources for innovations application, overall advancement of science and education.

So to explore a relationship between the countries' level of economic growth and innovation progress is important for the assessment of current international macroeconomic stance and prospects of both as innovations and countries' development. At the same time innovations may play a key role in accelerating the developing and emerging countries' growth and diminishing economic differentiation.



\section{Figure 1. Average Global Innovation Index based on World Bank Income Group Classification, 2019-2020}

Source: developed by the author based on [3, pp. 215-394]

A comprehensive measurement of countries' innovation level is made by Cornell University, INSEAD, and the World Intellectual Property Organization in the annual «Global Innovation Index» reports. They contain extensive metrics on 131 countries and their economies around the world's innovation performance and takes into account 80 indicators that recognize the political climate, education, infrastructure, and business sophistication, to name a few.

Analysis of the index throughout 2019-2020 years presented in Figure 1 proves that high-income countries have the highest overall index, while low-income countries have the lowest overall index. It should be noted that the global development of innovative 
economies focuses more on the ability of countries to innovate in a dynamic environment hence why the economy's response to current globalization trends may dictate its long-term success.

Almost all of the top-performing economies are from high-income countries. The income gap is wide across all pillars and it continues to widen as one goes from high to middle to low income. This is foreseen, given the well-established link between innovation and growth.

Low- and middle-income economies' innovation systems face systemic challenges that deepen the innovation gap: insufficient levels of education, science and technology investments, often weaker science and industry links, limited inward knowledge flows, lower absorptive and creative capacity of domestic companies, difficult business environments and limited access to financial resources.

Therefore, in most low-income economies, an important problem in the formation of an innovative economy is a gap between the stages of the innovation process. In particular, there is a problem between the number of scientific studies itself and at the later stage consequently their further implementation in production. This phenomenon of innovation gap between two groups of countries is generally attributed to two major factors:

1) scarcity of investments;

2) the lack of a mechanism for transforming existing scientific knowledge into working innovative ideas.

Anew the pressing issue of how the current pandemic of COVID-19 will affect these innovation divergences stands out in the ongoing innovation race. With the potential fragmentation of global value chains, weakened trade, and a global economic recession, the already made progress in terms of innovation convergence that has been made in recent years could come to a pause or even change.

At the same time, the growing competition for developing markets, certain limited financial resources, the most successful will be those countries that will eventually be able to develop a highly efficient economy based on continuous improvement of investments, production processes, and, accordingly, innovations. 
In most, if not all, low-income countries in comparison to highincome ones all levels of economic management have to enforce serious attention to the attraction and application of innovations. Nowadays, economies show the troubling signs that the gap between developed and emerging economies is widening.

During the turbulent innovation environment, governmental policies in the sphere of innovation should focus on the implementation of innovations that will not only increase the economic efficiency of a country but also will accelerate economic development and its transition to the innovation economy.

\section{References:}

1. Dolfsma W., Duysters G., Costa I. (2009) Multinationals and emerging economies. The quest for innovation and sustainability. Cheltenham, UK: Edward Elgar.

2. Oslo manual 2018: Guidelines for collecting, reporting and using data on innovation (2018). Paris: OECD Publishing.

3. Cornell University, INSEAD, and WIPO (2020). The Global Innovation Index 2020: Who Will Finance Innovation? Ithaca, Fontainebleau, and Geneva. 